\title{
Kajian Bundaran Mulyosari Menjadi Simpang Bersinyal
}

\author{
Rachmad Basuki, Fiany Dara Novelita, Endah Tri Listiari \\ Program Studi Diploma Teknik Sipil FTSP ITS \\ Email: rabas64@yahoo.co.id
}

\begin{abstract}
Mulyosari roundabout becomes the liaison of residential area, education and shopping center in Mulyosari and surrounding areas. The construction of new activity centers in the region brings consequences to the increased volume of vehicles in the Mulyosari Roundabout. In this paper will be presented evaluation results on the performance of Mulyosari roundabout. The data used include geometric data, traffic flow, environmental conditions, location map, population number, and growth of motor vehicles. Further analyzed in accordance with existing methods in MKJI 1997 with the help of KAJI program to calculate the volume on the existing condition. Results obtained in 2017 obtained DS> 0.75 on one part of the roundabout, so that the performance changes to be a signal intersection. With the improvement to 3 phases, obtained DS> 0.75 on all approaches and Level of Service (LOS) intersection is C. While in the projection of 2019-2021 obtained LOS D, then in 2022 obtained LOS E.
\end{abstract}

Keywords: Mulyosari Roundabout, MKJI 1997, Signal Intersection.

Abstrak

Bundaran Mulyosari menjadi penghubung kawasan permukiman, pendidikan dan pusat perbelanjaan di wilayah Kecamatan Mulyosari dan sekitarnya. Pembangunan pusat-pusat kegiatan baru di kawasan tersebut membawa konsekwensi terhadap meningkatnya volume kendaraan di Bundaran Mulyosari. Pada makalah ini akan disajikan hasil evaluasi terhadap kinerja Bndaran Mulyosari. Data yang digunakan meliputi data geometrik, arus lalu-lintas, kondisi lingkungan, peta lokasi, jumlah penduduk, dan pertumbuhan kendaraan bermotor. Selanjutnya dianalisis sesuai dengan metode yang ada pada MKJI 1997 dengan bantuan program KAJI untuk menghitung volume pada kondisi eksisting. Hasil yang didapatkan pada tahun 2017 didapatkan DS > 0,75 pada salah satu bagian jalinan bundaran, sehingga dilakukan perubahan kinerja menjadi simpang bersinyal. Dengan perbaikan menjadi 3 fase, didapatkan DS > 0,75 pada semua pendekat dan Level of Service (LOS) simpang adalah C. Sedangkan pada proyeksi tahun 2019-2021 didapatkan LOS D, lalu pada tahun 2022 didapatkan LOS E.

Kata kunci: Bundaran Mulyosari, MKJI 1997, Simpang Bersinyal.

\section{Pendahuluan}

Pembangunan pada suatu lokasi, baik pembangunan gedung perkantoran, gedung tinggal, maupun gedung sekolah pasti akan menimbulkan dampak dan pengaruh terhadap arus lalu lintas yang ada disekitarnya. Dengan semakin banyaknya pembangunan yang terjadi di Kota Surabaya, maka perlu adanya tinjauan ulang atau evaluasi terhadap pra- sarana transportasi sebagai penunjang mobilisasi masyarakat Surabaya. Evaluasi tersebut dilakukan di bundaran Mulyosari yang merupakan penghubung dari daerah pemukiman Mulyosari, area kampus Institut Teknologi Sepuluh Nopember, pusat perbelanjaan East Coast, komplek perumahan Pakuwon City, serta yang sedang dalam tahap rencana pembangunan yaitu Apartemen 
Grand Dharmahusada Laagon. Padahal keberadaan dan peran bundaran Mulyosari sangat penting bagi dinamisasi lalu lintas masyarakat sekitar yang menggunakan akses bundaran tersebut. Karena disekitar bundaran tesebut memang banyak lokasi strategis yang mengakibatkan mobilisasi masyarakat semakin bertambah dan berkembang.

Dari permasalahan tersebut, berkemungkinan nantinya akan terjadi peningkatan volume kendaraan pada bundaran tersebut dalam waktu yang cukup singkat. Maka tidak dapat dibayangkan terjadinya kepadatan arus lalu lintas yang terjadi disekitar bundaran Mulyosari. Sehingga kondisi eksisting bundaran Mulyosari perlu dilakukan evaluasi dari kinerja pengaturan lalu lintas menjadi simpang bersinyal. Hasil dari evaluasi yang dilakukan dapat menjadi solusi terbaik untuk menghindari kemacetan beberapa tahun kedepan dan menjadikan perilaku masyarakat dalam berkendara menjadi lebih teratur.

\section{Metodologi}

\subsection{Data Primer}

a. Data geometrik lalu lintas

Data geometrik meliputi data lebar masing - masing pendekat, data lebar median, data bahu jalan, data lebar bundaran. Data - data tersebut didapat dari instansi terkait yaitu dari Badan Perencanaan Pembangunan Kota (Bappeko) atau melakukan survey langsung ke lapangan.

b. Data volume lalu lintas
Data volume lalu lintas didapat dari hasil survei lapangan langsung, yaitu menghitung volume kendaraan dengan arus pada masing - masing pendekat, seperti arus kendaraan lurus, arus kendaraan belok kanan (RT), arus kendaraan belok kiri mengikuti traffic light (LT), atau belok kiri langsung (LTOR) yang meliputi:

- MC (Motor Cycle) atau sepeda motor

- LV (Light Vehicle) atau kendaraan ringan

- HV (Heavy Vehicle) atau kendaraan berat

- UM (Unmotorizhed) atau kendaraan tak bermesin

pada masing - masing pendekat dan pada saat jam puncak, yaitu antara pukul 06.00 - 09.00, $11.00-14.00$, dan $16.00-19.00$.

c. Data kondisi lingkungan

Data kondisi lingkungan yang dimaksud adalah daerah disekitar bundaran dimana kondisi lingkungan ini mempengaruhi tingkat hambatan samping. Dan termasuk data tata guna lahan apakah tipe lingkungan jalan komersial (COM), pemukiman (RES), atau akses terbatas (RA).

\subsection{Data Sekunder}

a. Peta lokasi

Data peta lokasi bundaran diperoleh dari situs google earth, ataupun wikimapia.

b. Data jumlah penduduk

Data jumlah penduduk diperoleh dari instansi terkait, yaitu Badan Pusat Statistik (BPS) Kota Surabaya atau 
Dinas Pencatatan Kependudukan dan Catatan Sipil (Dispendukcapil).

c. Data pertumbuhan kendaraan bermotor

Data pertumbuhan kendaraan bermotor diperoleh dari instansi terkait, yaitu Dinas Perhubungan (Dishub) Kota Surabaya.

\subsection{Survey Volume Kendaraan}

Survey volume kendaraan dilakukan untuk mendapatkan data volume lalu lintas dengan cara menghitung volume kendaraan pada sewtiap arah pergerakan pada masing - masing pendekat. Metode survey yang digunakan untuk menghitung volume kendaraan dengan menggunakan kamera dan survei secara manual. Survei menggunakan kamera dilakukan agar semua kendaraan dari semua pendekat dapat terekam arah pergerakannya, sehingga dapat mempermudah menghitung jumlah kenda- raan keseluruhan secara akurat. Kamera diletakkan diketinggian agar terlihat lalu lintas dari pergerakan seluruh pendekat pada bundaran. Survei secara manual dilakukan dengan menghitung kendaraan di setiap arah pergerakan pada bundaran dengan menggunakan rekaman video yang didapat dari survei menggunakan kamera.

Survey dilakukan di bundaran Mulyosari, dengan merekam kendaraan dari 3 arah pendekat dengan masing-masing pergerakannya. Kamera yang digunakan berjumlah dua buah diletakkan pada satu titik seperti pada gambar 3.1. Kamera satu berfungsi untuk merekam pergerakan dari arah Jl. Mulyosari dan sebagian Jl. Raya ITS. Kamera dua berfungsi untuk merekam pergerakan dari arah Jl. Kejawan Tambak Putih dan J1. Raya ITS. Kedua kamera mulai merekam dalam waktu yang bersamaan.

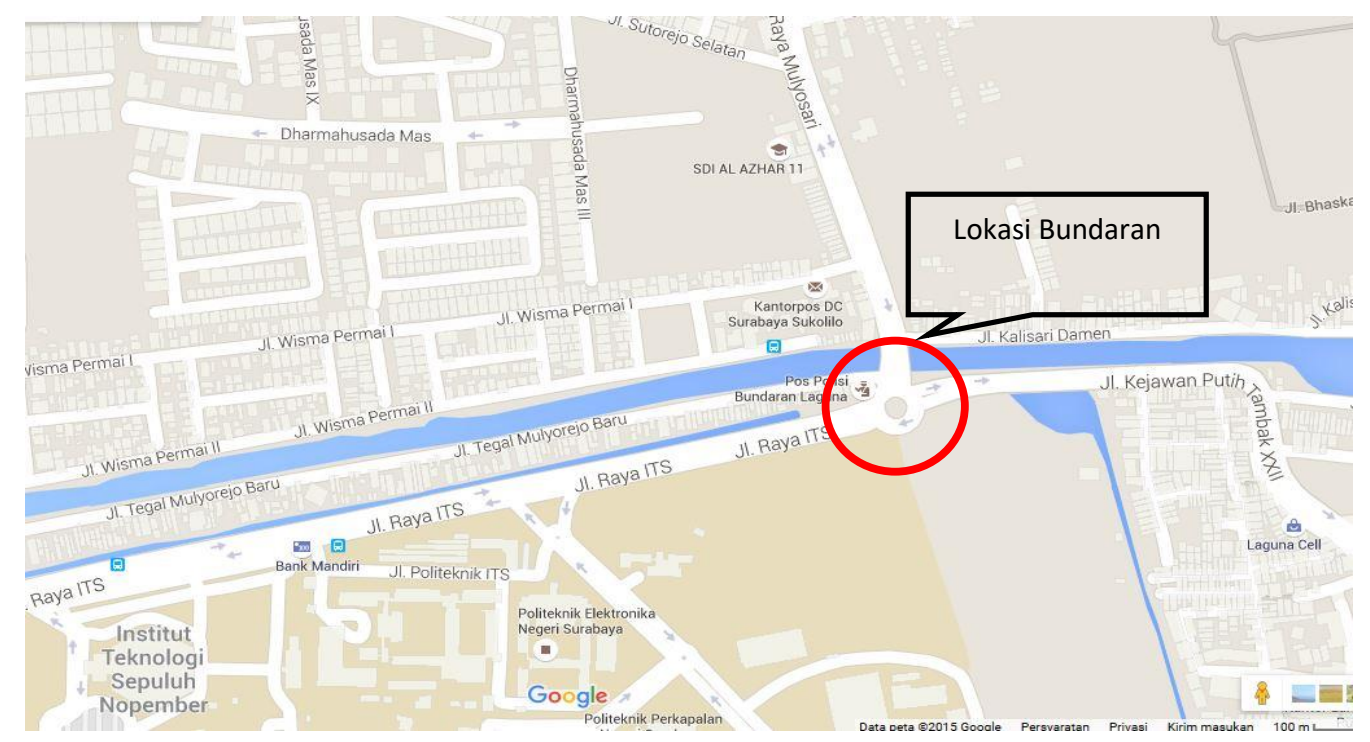

Gambar 1. Lokasi Bundaran Mulyosari 


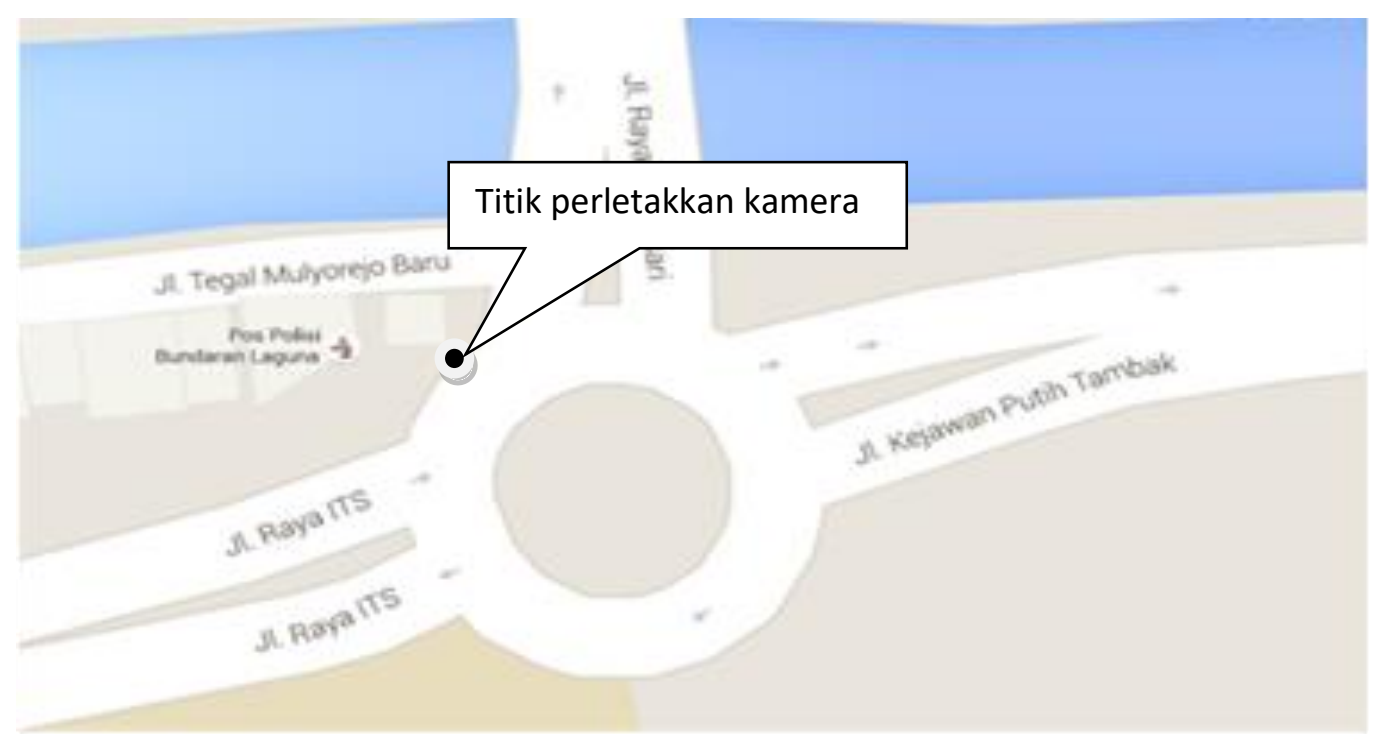

Gambar 2. Titik Perletakan Kamera

\section{Hasil dan Pembahasan}

\subsection{Analisa Pertubuhan Kendaraan}

Prediksi pertumbuhan regional sangat diperlukan khususnya untuk mengetahui transportasi yang akan datang. Pada Tabel 1 adalah data jumlah kendaraan di Surabaya.

Tabel 1. Data Jumlah Kendaraan Terdaftar di Surabaya

\begin{tabular}{cccc}
\hline Tahun & $\begin{array}{c}\text { Mobil } \\
(\mathrm{LV})\end{array}$ & $\begin{array}{c}\text { Truk } \\
(\mathrm{HV})\end{array}$ & $\begin{array}{c}\text { Sepeda } \\
\text { Motor } \\
(\mathrm{MC})\end{array}$ \\
\hline 2010 & 279116 & 91809 & 1213457 \\
2011 & 275930 & 94542 & 1274660 \\
2012 & 294780 & 103295 & 1402190 \\
2013 & 329555 & 117721 & 1615535 \\
2014 & 378059 & 127476 & 1953358 \\
\hline
\end{tabular}

Sumber: Dinas Perhubungan (Dishub) Kota Surabaya. 2015

Dalam memprediksi tingkat partumbuhan kendaraan dilakukan dengan dua cara, yaitu:

1. Metode regresi

2. Menggunakan asusmsi per-tumbuhan kendaraan pertahun di Surabaya
Data LHR (Lalu Lintas Harian Rata rata) pada Tabel 1 merupakan data sekunder yang dikunakan untuk mencari nilai preosentase pertumbhan kendaraan pada tiap tahunnya, kemudian hasil prosentase tersebut dikalikan dengan volume kendaraan dari survey langsung di lapangan yang merupakan data primer.

Analisa regresi untuk pertumbuhan LV dapat dilihat dari gambar 3 .

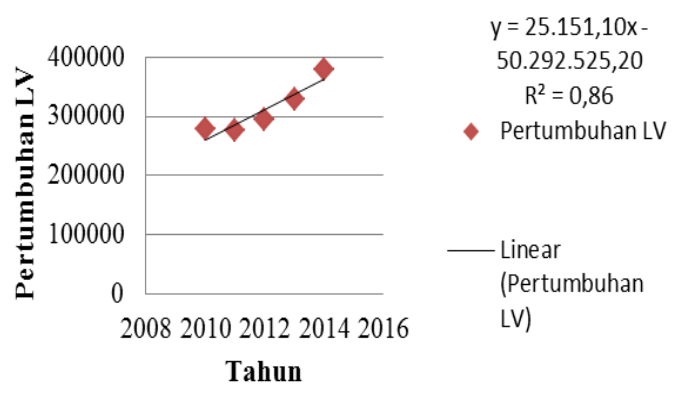

Gambar 3. Regresi Pertumbuhan Kendaraan Penumpang (LV)

Analisa regresi untuk pertumbuhan HV dapat dilihat dari gambar 4. 


\section{ISSN. 1907-753X}

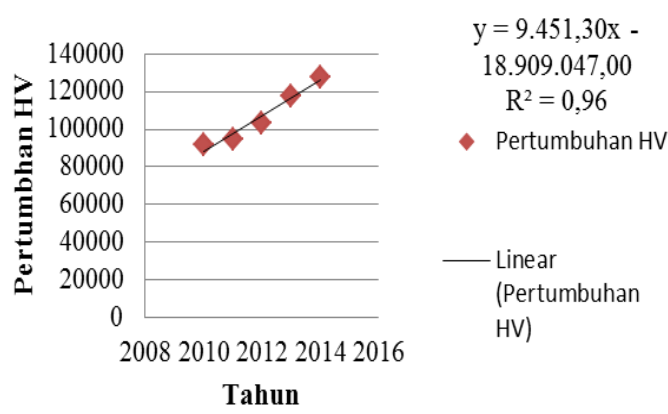

Gambar 4. Regresi Pertumbuhan Kendaraan Berat (HV)

Analisa regresi untuk pertumbhan MC dapat dilihat dari gambar 5 .

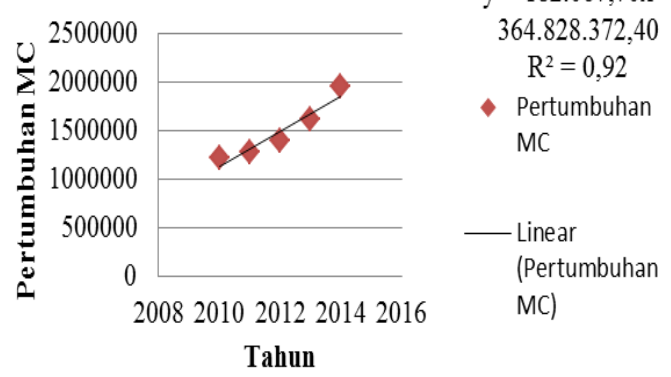

Gambar 5. Regresi Pertumbuhan Sepeda Motor (MC)

\subsection{Analisa Kondisi Lalu Lintas Bundaran Eksisting Tahun 2016}

Data kondisi lalu lintas didapatkan dari survey volume lalu lintas dengam menghitung jumlah kendaraan yang mendekati bundaran dalam jam-jam puncak tanggal 2 Maret 2016 dan 5 Maret 2016.

Data volume lalu lintas tersebut diolah dengan mencari jam puncak, kemudian dari jam puncak akan diperoleh volume kendaraan setiap pergerakan dari masing-masing pendekat. Hasil pengolahan data volume kendaraan dari setiap pergerakan pada hari kerja jam puncak tercatat dalam tabel 2.
Data-data kondisi geometrik bundaran didapatkan dari hasil survey lapangan. Hasil survey tersebut dapat digambar seperti pada gambar 6 .

a. Kapasitas

Meurut MKJI 1997, kapasitas (smp/jam), dihitung dengan menggunakan persamaan berikut:

$\mathrm{C}=\mathrm{C}_{0} \times \mathrm{F}_{\mathrm{CS}} \times \mathrm{F}_{\mathrm{RSU}}$

Kapasitas pada bagian jalinan $\mathrm{AB}$ adalah 5478 smp/jam, jalinan BC 4580 smp/jam, dan jalinan CA 7228 smp/jam yang terjadi saat puncak pagi, siang, dan sore pada hari kerja.

b. Derajat Kejenuhan (DS)

Derajat kejenuhan bundaran didefnisikan sebagai derajat kejenuhan bagian jalinan yang tertinggi, menurut MKJI 1997. Nilai derajat kejenuhan dihitung dari persamaan berikut:

$\mathrm{DS}=\mathrm{Q}_{\mathrm{smp}} / \mathrm{C}$

Derajat Kejenuhan (DS) pada bagian jalinan $\mathrm{AB}$ adalah 0,541, jalinan $\mathrm{BC}$ 0,729, dan jalinan CA 0,397 yang terjadi saat puncak pagi pada hari kerja. Pada puncak siang hari kerja DS bagian jalinan $\mathrm{AB}$ adalah 0,408, jalinan $\mathrm{BC}$ 0,480, dan jalinan CA 0,279. Dan pada puncak sore hari kerja DS bagian jalinan $\mathrm{AB}$ adalah 0,441 , jalinan $\mathrm{BC}$ 0,501 , dan jalinan CA 0,334 .

c. Tundaan

Menurut MKJI 1997, tundaan lalu lintas bagian jalinan adalah tundaan rata-rata lalu lintas per kendaraan yang masuk ke bagian jalinan. Teredapat hubungan empiris antara tundaan lalu-lintas dengan derajat kejenuhan. 
Tabel 2. Rekapitulasi Hasil Survey Lalu Lintas Hari Kerja Untuk 1 Jam Puncak

\begin{tabular}{|c|c|c|c|c|c|c|c|c|c|}
\hline \multirow{2}{*}{ Persimpangan } & \multirow{2}{*}{ Periode } & \multirow{2}{*}{ Pendekat } & \multirow{2}{*}{$\begin{array}{c}\text { Kode } \\
\text { Pendekat }\end{array}$} & \multirow{2}{*}{ Pergerakan } & \multicolumn{4}{|c|}{ Volume Kendaraan (kend/jam) } & \multirow{2}{*}{$\begin{array}{c}\text { Volume } \\
\text { (smp/jam }\end{array}$} \\
\hline & & & & & LV & $\mathrm{HV}$ & $\mathrm{MC}$ & $\mathrm{UM}$ & \\
\hline \multirow{21}{*}{$\begin{array}{l}\text { Bundaran } \\
\text { Mulyosari }\end{array}$} & \multirow{7}{*}{$\begin{array}{c}\text { Puncak } \\
\text { Pagi }\end{array}$} & \multirow{3}{*}{ Utara } & \multirow{3}{*}{ B } & LT (belok kiri) & 718 & 0 & 878 & 12 & 1157 \\
\hline & & & & RT (belok kanan) & 324 & 0 & 696 & 3 & 672 \\
\hline & & & & UT (putar balik) & 57 & 0 & 67 & 0 & 91 \\
\hline & & \multirow{2}{*}{ Timur } & \multirow{2}{*}{$\mathrm{C}$} & ST (lurus) & 1052 & 1 & 656 & 27 & 1381 \\
\hline & & & & RT (belok kanan) & 468 & 0 & 514 & 10 & 725 \\
\hline & & \multirow{2}{*}{ Barat } & \multirow{2}{*}{ A } & LT (belok kiri) & 387 & 0 & 679 & 1 & 727 \\
\hline & & & & ST (lurus) & 1059 & 9 & 700 & 7 & 1421 \\
\hline & \multirow{7}{*}{$\begin{array}{c}\text { Puncak } \\
\text { Siang }\end{array}$} & \multirow{3}{*}{ Utara } & \multirow{3}{*}{ B } & LT (belok kiri) & 314 & 1 & 521 & 10 & 576 \\
\hline & & & & RT (belok kanan) & 313 & 0 & 566 & 3 & 596 \\
\hline & & & & UT (putar balik) & 77 & 1 & 82 & 0 & 119 \\
\hline & & \multirow{2}{*}{ Timur } & \multirow{2}{*}{$\mathrm{C}$} & ST (lurus) & 511 & 11 & 466 & 9 & 758 \\
\hline & & & & RT (belok kanan) & 330 & 5 & 444 & 2 & 559 \\
\hline & & \multirow{2}{*}{ Barat } & \multirow{2}{*}{ A } & LT (belok kiri) & 322 & 2 & 655 & 4 & 652 \\
\hline & & & & ST (lurus) & 657 & 6 & 483 & 2 & 906 \\
\hline & \multirow{7}{*}{$\begin{array}{c}\text { Puncak } \\
\text { Sore }\end{array}$} & \multirow{3}{*}{ Utara } & \multirow{3}{*}{ B } & LT (belok kiri) & 351 & 2 & 678 & 14 & 693 \\
\hline & & & & RT (belok kanan) & 339 & 1 & 629 & 2 & 655 \\
\hline & & & & UT (putar balik) & 54 & 0 & 66 & 1 & 87 \\
\hline & & \multirow{2}{*}{ Timur } & \multirow{2}{*}{$\mathrm{C}$} & ST (lurus) & 586 & 5 & 778 & 14 & 982 \\
\hline & & & & RT (belok kanan) & 399 & 1 & 580 & 7 & 690 \\
\hline & & \multirow{2}{*}{ Barat } & \multirow{2}{*}{ A } & LT (belok kiri) & 410 & 1 & 743 & 5 & 783 \\
\hline & & & & ST (lurus) & 571 & 0 & 573 & 4 & 858 \\
\hline
\end{tabular}

Sumber: Hasil Perhitungan

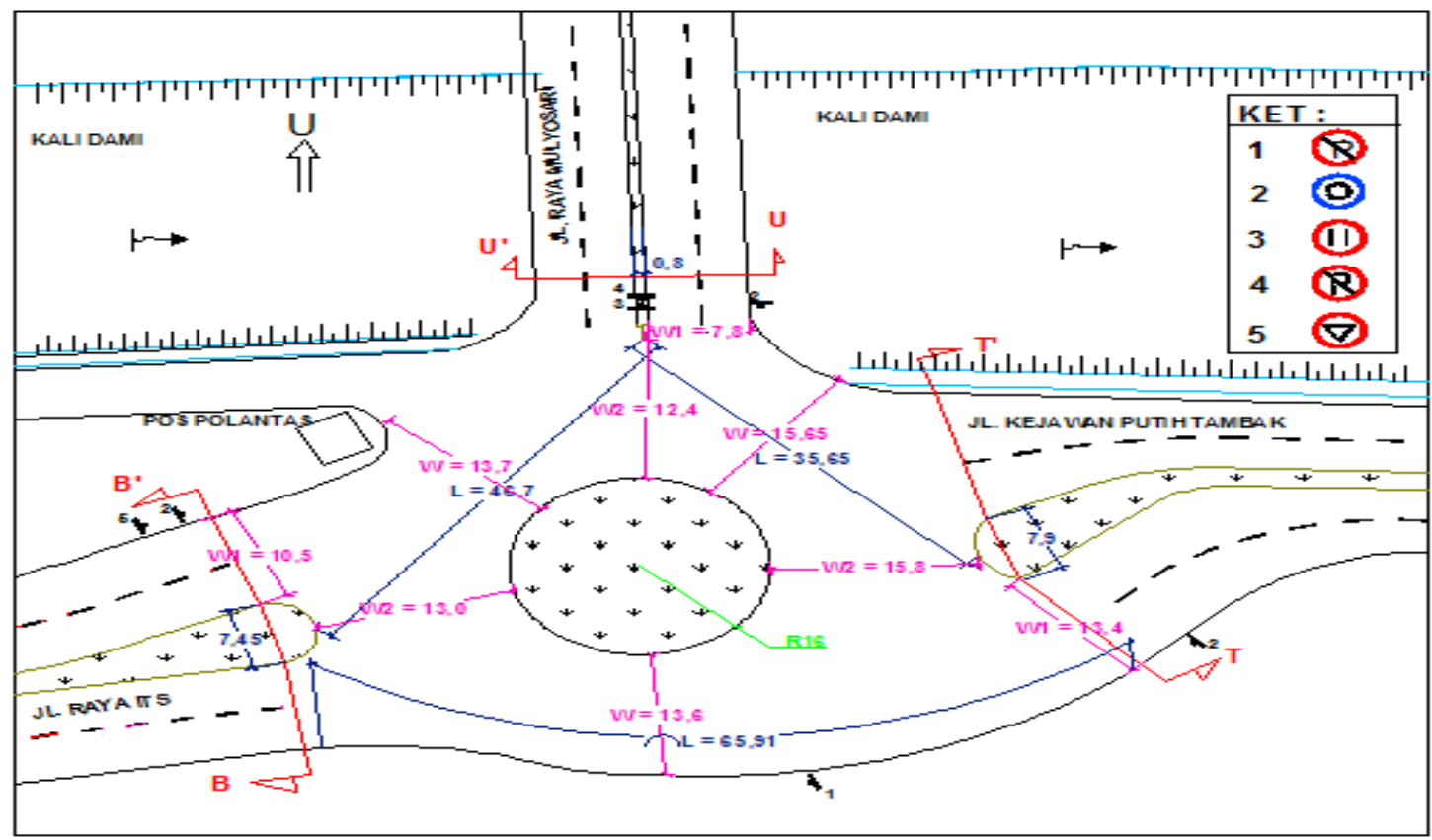

Gambar 1. Geometrik Bundaran Mulyosari

Tundaan bagian jalinan bundaran pada puncak pagi hari kerja jalinan $\mathrm{AB}$ adalah 2,54 det/smp, jalinan BC 4,25 det/smp, jalinan CA 1,68 det/smp. Pada puncak siang tundaan bagian jalinan $\mathrm{AB}$ adalah 1,97 det/smp, jalinan BC 2,35 $\mathrm{det} / \mathrm{smp}$, jalinan CA 1,29 det/smp. Dan pada puncak sore tundaan bagian jalinan 
AB adalah 2,15 det/smp, jalinan BC 2,44 det/smp, jalinan CA 1,65 det/smp.

\section{d. Peluang Antrian}

Peluang antrian pada puncak pagi hari kerja bagian jalinan $\mathrm{AB}$ adalah 7 $15 \%$, jalinan BC $14-32 \%$, jalinan CA $4-8 \%$. Pada puncak siang peluang antrian jalinan $\mathrm{AB} 4-9 \%$, jalinan $\mathrm{BC} 6$ - $12 \%$, jalinan CA $2-6 \%$. Dan pada puncak sore peluang antrian jalinan $\mathrm{AB}$ $5-10 \%$, jalinan BC $5-16 \%$, dan jalinan CA $4-6 \%$.

Berikut ini adalah hasil evaluasi bundaran Mulyosari untuk lima tahun kedepan tercatat dalam Tabel 3 untuk hari kerja jam puncak pagi, Tabel 4 untuk jam puncak siang, dan Tabel 5 untuk jam puncak sore.

Tabel 3. Rekapitulasi Hasil Evaluasi Bundaran Mulyosari Hari Kerja Tahun 2017-2021 Jam Puncak Pagi

\begin{tabular}{|c|c|c|c|c|c|}
\hline \multirow[b]{2}{*}{ Tahun } & \multirow[b]{2}{*}{ Jalinan } & \multirow[b]{2}{*}{$\begin{array}{c}\text { Kapasi- } \\
\text { tas } \\
\text { (smp/jam) }\end{array}$} & \multicolumn{3}{|c|}{ Tundaan } \\
\hline & & & $\begin{array}{c}\text { Derajat } \\
\text { Kejenu- } \\
\text { han } \\
\text { (DS) }\end{array}$ & $\begin{array}{c}\text { Lalu- } \\
\text { Lintas } \\
\text { Jalinan } \\
\text { (det/ } \\
\text { smp) }\end{array}$ & $\begin{array}{c}\text { Peluang } \\
\text { Antrian } \\
(\%)\end{array}$ \\
\hline \multirow{3}{*}{2017} & $\mathrm{AB}$ & 5479 & 0,578 & 2,85 & $8-18$ \\
\hline & $\mathrm{BC}$ & 4580 & 0,779 & 5,18 & $16-38$ \\
\hline & $\mathrm{CA}$ & 7226 & 0,424 & 1,98 & $4-8$ \\
\hline \multirow{3}{*}{2018} & $\mathrm{AB}$ & 5479 & 0,614 & 3,25 & $8-20$ \\
\hline & $\mathrm{BC}$ & 4581 & 0,829 & 6,31 & $20-46$ \\
\hline & $\mathrm{CA}$ & 7225 & 0,451 & 1,98 & $4-10$ \\
\hline \multirow{3}{*}{2019} & $\mathrm{AB}$ & 5480 & 0,651 & 3,43 & $10-24$ \\
\hline & $\mathrm{BC}$ & 4581 & 0,879 & 7,48 & $24-54$ \\
\hline & $\mathrm{CA}$ & 7225 & 0,478 & 2,27 & $6-11$ \\
\hline \multirow{3}{*}{2020} & $\mathrm{AB}$ & 5480 & 0,688 & 3,97 & $12-28$ \\
\hline & $\mathrm{BC}$ & 4581 & 0,929 & 9,63 & $30-64$ \\
\hline & $\mathrm{CA}$ & 7225 & 0,505 & 2,26 & $6-12$ \\
\hline \multirow{3}{*}{2021} & $\mathrm{AB}$ & 5480 & 0,725 & 4,25 & $14-32$ \\
\hline & $\mathrm{BC}$ & 4581 & 0,979 & 12,97 & $36-74$ \\
\hline & $\mathrm{CA}$ & 7225 & 0,533 & 2,48 & $5-13$ \\
\hline
\end{tabular}

Sumber: Hasil Perhitungan

\subsection{Analisa Perbaikan Kinerja Bundaran Mulyosari Menjadi Simpang Bersinyal Tahun 2017}

Dari hasil evaluasi kondisi eksisting bundaran Mulyosari, diperlukan perubahan kinerja menjadi simpang bersinyal dimulai tahun 2017. Maka, direncanakan perubahan geometrik simpang dan pengaturan 3 fase seperti yang tergambar pada gambar 7 dan gambar 8 .

- $\quad$ Pendekat Utara (LTOR)

$\begin{array}{ll}\mathrm{W}_{\text {Pendekat }} & =7,8 \mathrm{~m} \\ \mathrm{~W}_{\text {Masuk }} & =5,3 \mathrm{~m} \\ \mathrm{~W}_{\text {Keluar }} & =10 \mathrm{~m} \\ \mathrm{~W}_{\text {LTOR }} \geq 2 \mathrm{~m} & =2,5 \mathrm{~m}\end{array}$

Tabel 4. Rekapitulasi Hasil Evaluasi Bundaran Mulyosari Hari Kerja Tahun 2017-2021 Jam Puncak Siang

\begin{tabular}{|c|c|c|c|c|c|}
\hline \multirow[b]{2}{*}{ Tahun } & \multirow[b]{2}{*}{ Jalinan } & \multirow[b]{2}{*}{$\begin{array}{c}\text { Kapasi- } \\
\text { tas } \\
\text { (smp/jam) }\end{array}$} & \multicolumn{3}{|c|}{ Tundaan } \\
\hline & & & $\begin{array}{c}\text { Derajat } \\
\text { Kejenu- } \\
\text { han } \\
\text { (DS) }\end{array}$ & $\begin{array}{c}\text { Lalu- } \\
\text { Lintas } \\
\text { Jalinan } \\
\text { (det/ } \\
\text { smp) }\end{array}$ & $\begin{array}{c}\text { Peluang } \\
\text { Antrian } \\
(\%)\end{array}$ \\
\hline \multirow{3}{*}{2017} & $\mathrm{AB}$ & 5520 & 0,433 & 2,17 & $4-10$ \\
\hline & $\mathrm{BC}$ & 4615 & 0,509 & 2,56 & $6-14$ \\
\hline & $\mathrm{CA}$ & 7281 & 0,290 & 1,42 & $2-6$ \\
\hline \multirow{3}{*}{2018} & $\mathrm{AB}$ & 5520 & 0,461 & 2,28 & $6-12$ \\
\hline & $\mathrm{BC}$ & 4615 & 0,541 & 2,64 & $7-16$ \\
\hline & $\mathrm{CA}$ & 7281 & 0,318 & 1,48 & $3-6$ \\
\hline \multirow{3}{*}{2019} & $\mathrm{AB}$ & 5520 & 0,488 & 2,48 & $6-12$ \\
\hline & $\mathrm{BC}$ & 4615 & 0,574 & 2,87 & $8-18$ \\
\hline & $\mathrm{CA}$ & 7281 & 0,337 & 1,56 & $3-6$ \\
\hline \multirow{3}{*}{2020} & $\mathrm{AB}$ & 5520 & 0,517 & 2,52 & $6-14$ \\
\hline & $\mathrm{BC}$ & 4615 & 0,607 & 2,97 & $8-20$ \\
\hline & $\mathrm{CA}$ & 7278 & 0,357 & 1,65 & $4-7$ \\
\hline \multirow{3}{*}{2021} & $\mathrm{AB}$ & 5520 & 0,564 & 2,74 & $8-16$ \\
\hline & $\mathrm{BC}$ & 4615 & 0,640 & 3,35 & $10-23$ \\
\hline & $\mathrm{CA}$ & 7224 & 0,427 & 2,1 & $4-9$ \\
\hline \multicolumn{6}{|c|}{ Sumber: Hasil Perhitungan } \\
\hline$\bullet$ & \multicolumn{5}{|c|}{ Pendekat Timur } \\
\hline & $\mathrm{W}_{\mathrm{Pe}}$ & dekat & & & $13,1 \mathrm{~m}$ \\
\hline
\end{tabular}




$$
\begin{array}{ll}
\mathrm{W}_{\text {Masuk }} & =6,1 \mathrm{~m} \\
\mathrm{~W}_{\text {Keluar }} & =7,6 \mathrm{~m}
\end{array}
$$

- $\quad$ Pendekat Barat (LTOR)

$$
\begin{array}{ll}
\text { W Pendekat } & =10,5 \mathrm{~m} \\
\mathrm{~W}_{\text {Masuk }} & =7 \mathrm{~m} \\
\mathrm{~W}_{\text {Keluar }} & =14,8 \mathrm{~m} \\
\mathrm{~W}_{\text {LTOR }} \geq 2 \mathrm{~m} & =3,5 \mathrm{~m}
\end{array}
$$

\section{a. Kapasitas}

Arus lalu-lintas maximum yang dapat dipertahankan (tetap) pada suatu bagian jalan dalam kondisi tertentu, misalnya:

\begin{tabular}{|c|c|c|c|c|c|}
\hline \multirow[b]{2}{*}{ Tahun } & \multirow[b]{2}{*}{ Jalinan } & \multirow[b]{2}{*}{$\begin{array}{c}\text { Kapasi- } \\
\text { tas } \\
\text { (smp/jam) }\end{array}$} & \multicolumn{3}{|c|}{ Tundaan } \\
\hline & & & $\begin{array}{c}\text { Derajat } \\
\text { Kejenu- } \\
\text { han } \\
\text { (DS) }\end{array}$ & $\begin{array}{c}\text { Lalu- } \\
\text { Lintas } \\
\text { Jalinan } \\
\text { (det/ } \\
\text { smp) }\end{array}$ & $\begin{array}{c}\text { Peluang } \\
\text { Antrian } \\
(\%)\end{array}$ \\
\hline \multirow{3}{*}{2017} & $\mathrm{AB}$ & 5479 & 0,472 & 2,4 & $5-12$ \\
\hline & $\mathrm{BC}$ & 4580 & 0,536 & 2,62 & $6-15$ \\
\hline & $\mathrm{CA}$ & 7226 & 0,357 & 1,61 & $4-7$ \\
\hline \multirow{3}{*}{2018} & $\mathrm{AB}$ & 5479 & 0,503 & 2,47 & $6-14$ \\
\hline & $\mathrm{BC}$ & 4581 & 0,571 & 2,78 & 8-18 \\
\hline & $\mathrm{CA}$ & 7225 & 0,381 & 1,75 & $4-8$ \\
\hline \multirow{3}{*}{2019} & $\mathrm{AB}$ & 5480 & 0,533 & 2,89 & $6-14$ \\
\hline & $\mathrm{BC}$ & 4581 & 0,605 & 2,62 & $8-20$ \\
\hline & $\mathrm{CA}$ & 7225 & 0,404 & 1,91 & $4-8$ \\
\hline \multirow{3}{*}{2020} & $\mathrm{AB}$ & 5480 & 0,564 & 2,74 & $8-16$ \\
\hline & $\mathrm{BC}$ & 4581 & 0,640 & 3,35 & $10-23$ \\
\hline & $\mathrm{CA}$ & 7224 & 0,427 & 2,1 & $4-9$ \\
\hline \multirow{3}{*}{2021} & $\mathrm{AB}$ & 5481 & 0,594 & 2,9 & $8-19$ \\
\hline & $\mathrm{BC}$ & 4581 & 0,675 & 3,58 & $11-26$ \\
\hline & $\mathrm{CA}$ & 7222 & 0,451 & 2,14 & $4-10$ \\
\hline
\end{tabular}
rencana geometrik, lingkungan, komposisi lalu-lintas dan sebagainya (MKJI 1997). Kapasitas dari masing-masing pendekat dapat dihitung dari persamaan dibawah ini:

$$
\mathrm{C}=\mathrm{S} \times \mathrm{g} / \mathrm{c}
$$

Hasil perhitungan dapat dilihat pada Tabel 5.

Tabel 5. Rekapitulasi Hasil Evaluasi Bundaran Mulyosari Hari Kerja Tahun 2017-2021 Jam Puncak Sore

Sumber: Hasil Perhitungan
Tabel 6. Rekapitulasi Kapasitas Simpang Bersinyal Tahun 2017

\begin{tabular}{cccc}
\hline \multirow{2}{*}{ Pendekat } & \multicolumn{3}{c}{ Kapasitas (smp/jam) } \\
\cline { 2 - 4 } & Puncak & Puncak & Puncak \\
\hline Utara & 710 & 927 & 713 \\
Timur & 889 & 771 & 775 \\
Barat & 1793 & 1352 & 1834 \\
\hline
\end{tabular}

b. Derajat Kejenuhan (DS)

Rasio arus lalu-lintas terhadap kapasitas (MKJI 1997). Nilai DS didapatkan dari persamaan berikut:

$$
\mathrm{DS}=\mathrm{Q} / \mathrm{C}
$$

Hasil perhitungan dapat dilihat pada Tabel 7.

Tabel 7. Rekapitulasi Derajat Kejenuhan Simpang Bersinyal Tahun 2017

\begin{tabular}{cccc}
\hline \multirow{2}{*}{ Pendekat } & \multicolumn{3}{c}{ Derajat Kejenuhan } \\
\cline { 2 - 4 } & Puncak & Puncak & Puncak \\
\hline Utara & 0,963 & 0,748 & 0,871 \\
Timur & 0,969 & 0,733 & 0,885 \\
Barat & 0,972 & 0,743 & 0,495 \\
\hline
\end{tabular}

\section{c. Panjang Antrian}

Panjang antrian (QL) diperoleh dari perkalian (NQMAX) dengan luas rata-rata yang dipergunakan per smp $\left(20 \mathrm{~m}^{2}\right)$ dan pembagian dengan lebar masuk sebagaimana persamaan dibawah ini.

$$
Q L=N Q_{\text {MAX }} \times \frac{20}{W_{\text {MASUK }}}
$$

Panjang antrian (QL) pada perencanaan simpang bersinyal tahun 2017 dapat dilihat pada Tabel 8 .

Waktu tempuh tambahan yang diperlukan untuk melewati suatu simpang dibandingkan terhadap situasi tanpa simpang (MKJI 1997). 

ISSN. 1907-753X

Tabel 8. Rekapitulasi Panjang Antrian Simpang Bersinyal Tahun 2017

\begin{tabular}{cccc}
\hline & \multicolumn{3}{c}{ Panjang Antrian (m) } \\
\cline { 2 - 4 } Pendekat & Puncak & Puncak & Puncak \\
\hline Utara & 98 & 72 & 83 \\
Timur & 98 & 62 & 82 \\
Barat & 171 & 66 & 57 \\
\hline
\end{tabular}

\section{d. Tundaan Rata-Rata}

Tundaan rata-rata (DI) didapatkan dari perhitungan persamaan sebagai berikut:

$$
D_{I}=\frac{\Sigma(Q \times D)}{Q_{T O T}}
$$

Hasil perhitungan dapat dilihat pada Tabel 9.

\section{e. Tingkat Pelayanan (LOS)}

Ukuran kwalitatif yang digunakan di menerangkan kondisi operasional dalam arus lalu-lintas dan penilaiannya oleh pemakai jalan (MKJI 1997).

\section{Simpulan}

Dari hasil kajian bundaran Mulyosari menjadi simpang bersinyal, maka dapat disimpulkan sebagai berikut:

1. Menurut data hasil survey yang telah dilakukan, diketahui volume kendaraan jam puncak pada Bundaran Mulyosari adalah sebesar 6173 smp/jam pada puncak pagi, $4156 \mathrm{smp} / \mathrm{jam}$ pada puncak siang, dan 4747 smp/jam pada puncak sore. Interval jam puncak pada Bundaran Mulyosari adalah puncak pagi dimulai pukul 06.50 - 07.50, puncak siang dimulai pukul $12.50-$ 13.50, dan puncak sore dimulai pukul 16.05-17.05.

HCM 85 Amerika Serikat dan

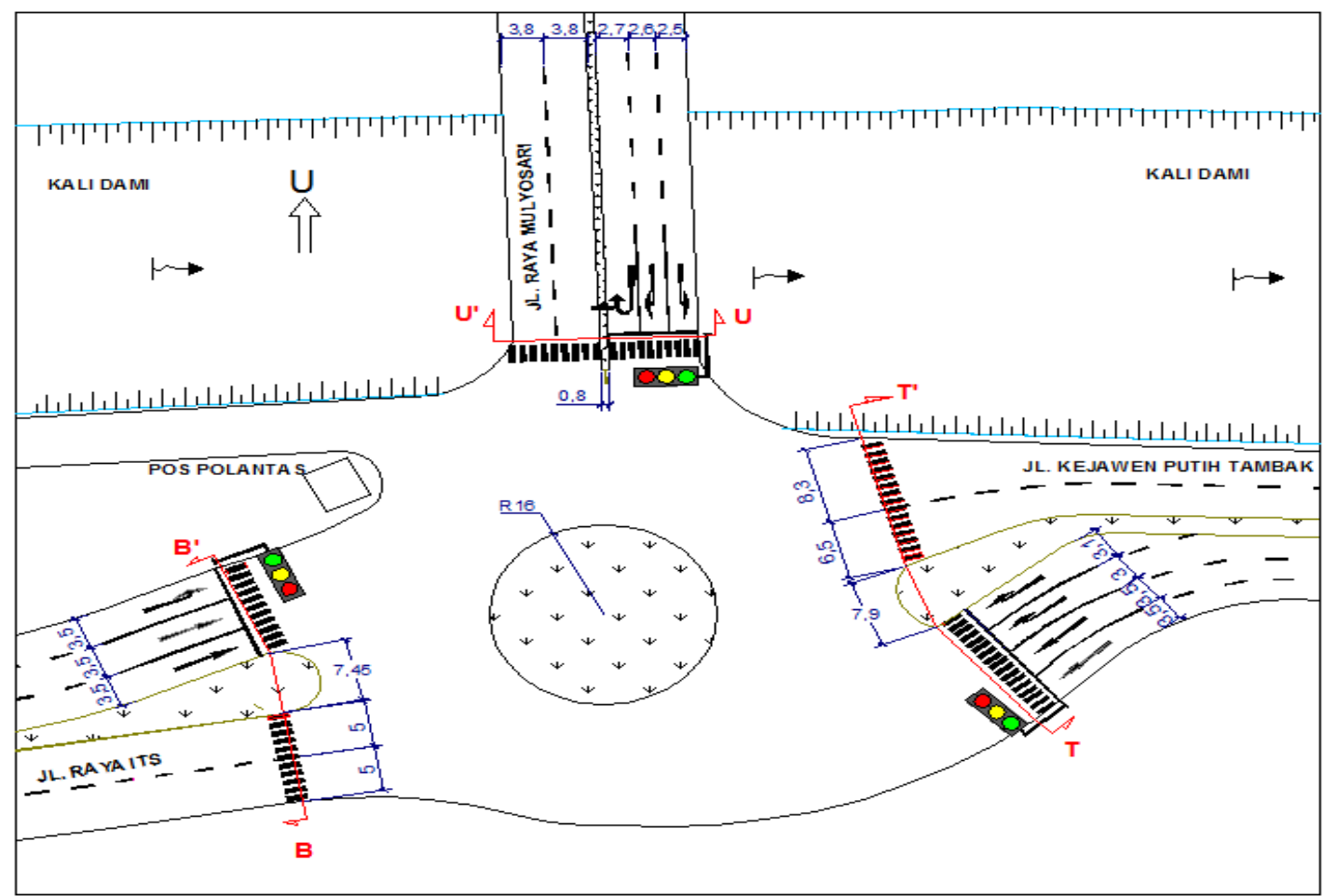

Gambar 2. Rencana Geometrik Simpang 
FASE 1

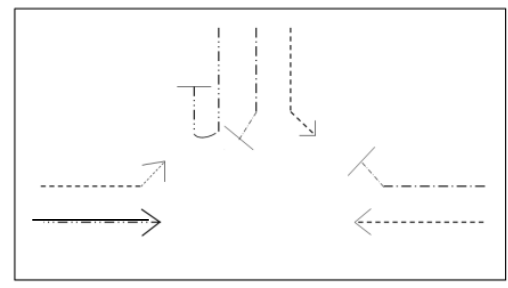

FASE 2

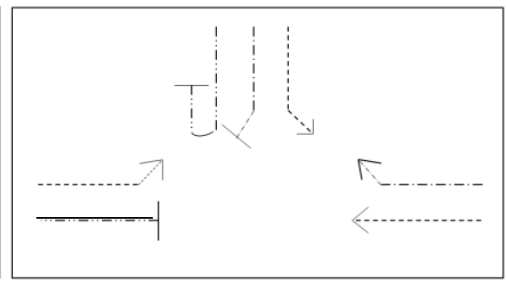

FASE 3

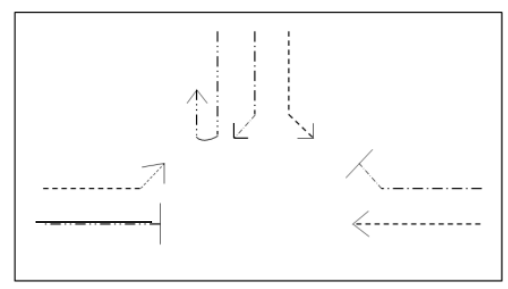

Gambar 3. Rencana Pengaturan Fase Simpang

Keterangan :

\begin{tabular}{|c|c|}
\hline$-\cdot-\cdot-\cdot$ & $=$ belok kanan \\
\hline$-\cdots-\cdots-$ & $=$ putar balik \\
\hline 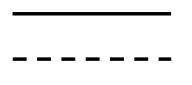 & $\begin{array}{l}=\text { lurus } \\
=\text { LTOR }\end{array}$ \\
\hline
\end{tabular}

Tabel 9. Rekapitulasi Tundaan Rata-Rata Simpang Bersinyal Tahun 2017

\begin{tabular}{cc}
\hline Pendekat & $\begin{array}{c}\text { Tundaan Rata-Rata (DI) } \\
\text { (det/smp) }\end{array}$ \\
\cline { 1 - 1 } $\begin{array}{cc}\text { Puncak } \\
\text { Pagi }\end{array}$ & 21,09 \\
$\begin{array}{c}\text { Puncak } \\
\text { Siang }\end{array}$ & 20,93 \\
$\begin{array}{c}\text { Puncak } \\
\text { Sore }\end{array}$ & 20,44 \\
\hline
\end{tabular}

Tabel 10. Rekapitulasi Tingkat Pelayanan Simpang Bersinyal Tahun 2017

\begin{tabular}{cc}
\hline Pendekat & Tingkat Pelayanan (LOS) \\
\hline Puncak & $\mathrm{C}$ \\
Pagi & \\
Puncak & $\mathrm{C}$ \\
Siang & \\
Puncak & $\mathrm{C}$ \\
Sore & \\
\hline
\end{tabular}

2. Berdasarkan hasil analisa kinerja Bundaran Mulyosari kondisi eksisting (hari kerja) tahun 2016 didapatkan DS $\leq 0,75$ pada semua jam puncak, yaitu puncak pagi, siang, dan sore. Hal ini mengindikasikan bahwa Bundaran Mulyosari masih layak dipertahankan sesuai dengan MKJI 1997.

3. Dari hasil analisa kondisi eksisting Bundaran Mulyosari, kinerja bundaran hanya bisa bertahan 1 tahun mulai dari tahun dilakukannya evaluasi kinerja eksisting, yaitu tahun 2016. Sehingga mulai tahun 2017 perlu dilakukan perbaikan dengan mengoperasikan simpang bersinyal. 
4. Berdasarkan hasil kinerja bundaran setelah menjadi simpang bersinyal dengan pengaturan 3 fase pada tahun 2017 puncak pagi $\mathrm{DS} \geq 0,75$. Pada pendekat barat, timur, dan utara didapatkan nilai DS $\mid 0,78$ 0,83 . Pada puncak siang dan sore $\mathrm{DS} \leq 0,75$. Namun pada puncak siang tahun 2022, pendekat barat, timur, dan utara didapatkan DS berkisar $|0,77-0,79|$ dan pada puncak sore tahun 2021, pendekat timur nilai DS adalah 0,777. Tundaan simpang (DI) pada tahun 2017 puncak pagi, puncak siang, dan puncak sore adalah |20,39 $21,09 \mid \mathrm{det} / \mathrm{smp}$. Tingkat pelayanan simpang pada tahun 2017 puncak pagi, puncak siang, dan puncak sore adalah LOS C. Panjang antrian (QL) maksimum pada tahun 2017 sebesar $120 \mathrm{~m}$. Alternatif simpang bersinyal 3 fase ini cukup baik sesuai dengan MKJI 1997. Dari evaluasi rencana perbaikan didapatkan LOS D pada tahun 2019-2021, dan pada tahun 2022 didapatkan LOS E.

\section{Daftar Pustaka}

Alamsyah, Alik Ansyori. 2005. Rekayasa Lalu Lintas. UMM Press.

Departement Pekerjaan Umum, Direktorat Jendral Bina Marga. 1997. Manual Kapasitas Jalan Indonesia: PT. Bina Karya (PERSERO)

Departement Pekerjaan Umum, Direktorat Jendral Bina Marga. 1991. Tata Cara Pemasangan Rambu dan Marka Jalan Perkotaan.
Hartono. 2004. Statistik untuk Penelitian. Yogyakarta: Pustaka Pelajar.

Machsus, Mukafi, 2013. Kajian Kebutuhan Ruang Parkir pada Mall Galaxy di Kota Surabaya. Prosiding Seminar Nasional ATPW ITS,

https://atpw.files.wordpress.com/2 013/03/a19-kajian-kebutuhanruang-parkir-di-galaxy-mallsurabaya.pdf

Machsus, Basuki R., 2008. Penggunaan BBG pada Kendaraan Bermotor di Kota Surabaya. Jurnal Aplikasi Teknik Sipil, 4(1), pp. 51-60. DOI: http://dx.doi.org/10.12962/j12345 678.v4i1.2767

Machsus, Rachmad Basuki, and Amalia F. Mawardi, 2015. "Generalized Additive Models for Estimating Motorcycle Collisions on Collector Roads". The 5th International Conference of Euro Asia Civil Engineering Forum (EACEF-5), doi:10.1016/j.proeng.2015.11.105, ISSN: 1877-7058, September 1518, 2015, Surabaya, Indonesia.

Machsus, Harnen S., Wicaksono A., and Djakfar L., 2013. The Prediction Models of Motorcycle Accidents on Surabaya Arterial Roads Using Generalized Linear Models. Middle-East J. Sci. Res., 18 (12): 1859-1866, 2013. ISSN 19909233, (C IDOSI Publications.

Machsus, Harnen Sulistio, Achmad Wicaksono and Ludfi Djakfar. 2014. "The Effect of Access Points on Motorcycle Accident Rates on Surabaya Arterial Roads". 
Australian Journal of Basic and Applied Sciences (AJBAS), 8 (10), 38-43

Mawardi, A.F., Herijanto, W., Maharani, M., 2012. Analisis Kapasitas Parkir dan Antrian dengan adanya Sistem Portal Otomatis di Pusat Perbelanjaan (Studi Kasus Gedung Pusat Grosir Solo). Jurnal Aplikasi Teknik Sipil, 10(1), pp. 51-60. DOI:http://dx.doi.org/10.12962/j1 2345678.v10i1.2684
Sudjana. 2005. Metode Statistika. Bandung: Tarsito. 